\title{
PELATIHAH DASAR PENGGUNAAN APLIKASI MICROSOFT OFFICE DAN PAINT DI SEKOLAH DASAR NEGERI 1 UMEANYAR
}

\author{
Gede Beny Indrawan ${ }^{1}$, Gusti Ayu Gita Mulya Sari ${ }^{2}$, Kadek Utari Darma Putri ${ }^{3}$, \\ Dwi Prima Handayani Putri ${ }^{4}$, Luh Joni Erawati Dewi ${ }^{5}$ \\ 1,2,3,4,5 Program Studi IImu Komputer, Universitas Pendidikan Ganesha \\ e-mail: beny.indrawan@undiksha.ac.id, ayu.gita.mulya@undiksha.ac.id, \\ utari.darma@undiksha.ac.id, dwi.prima@undiksha.ac.id, joni.erawati@undiksha.ac.id
}

\begin{abstract}
Abstrak
Kegiatan pengabdian pada masyarakat (P2M) ini dilaksanakan dengan tujuan untuk memberikan pemahaman tentang pentingnya teknologi, serta memberikan pelatihan untuk meningkatkan keterampilan dasar pengoperasian komputer dan penggunaan aplikasi fundamental komputer, seperti Paint, Microsoft Office Word dan Microsoft Office Powerpoint kepada siswa kelas 4, 5, dan 6 Sekolah Dasar Negeri 1 Umeanyar. Metode pelaksanaan kegiatan ini dilakukan dengan menggunakan metode ceramah dan diskusi antara siswa dan pemateri, serta pemberian praktikum terkait cara penggunaan komputer untuk menguji pemahaman siswa mengenai materi yang telah disampaikan sebelumnya. Hasil kegiatan ini adalah peningkatan pemahaman siswa tentang dasar pengoperasian komputer dan keterampilan siswa dalam menggunakan aplikasi fundamental komputer, diantaranya adalah penggunaan aplikasi Microsoft Office Power Point untuk membuat media interaktif dan penggunaan Microsoft Office Word untuk pembuatan dokumen.
\end{abstract}

Kata kunci: Gen A, kondisi ideal, pelatihan, teknologi

\begin{abstract}
This community service activity (P2M) was carried out with the aim of providing an understanding of the importance of technology, as well as providing training to enhanced basic computer operating skills and enhanced skills in using the fundamental computer applications, such as Paint, Microsoft Office Word and Microsoft Office Powerpoint for $4_{\text {th, }} 5_{\text {th }}$, 6th grade student from Public Elementary School 1 Umeanyar. The method of implementing this activity is carried out using the lecture method and discussion between students and presenters, followed by practicum that is related to how to use computers to test students' understanding of the material that has been previously presented. The result of this activity is the students can understand basic computer operations and the improvement of students' skills in using basic computer applications, including the use of Microsoft Office PowerPoint applications to create interactive media product and the use of Microsoft Office Word to create documents.
\end{abstract}

Keywords : Gen A, ideal conditions, training, technology 


\section{PENDAHULUAN}

Generasi Alpha merupakan generasi yang lahir antara tahun 20112025 (Fadlurrohim et al., 2020). Generasi Alpha atau Gen A merupakan generasi yang paling akrab dengan teknologi. Keakraban tersebut terbukti dengan bagaimana lihainya anak-anak Gen A dalam menggunakan teknologi, salah satunya adalah gadget (Fadlurrohim et al., 2020).

Hal tersebut sebenarnya tidak menjadi masalah karena Gen A memang lahir dengan kondisi dimana teknologi telah berkembang pesat. Namun, pemanfaatan teknologi yang digunakan hanya terbatas pada pemenuhan kesengan diri dan bermain. Anak-anak zaman sekarang kebanyakan hanya bisa memanfaatkan teknologi terbatas pada penggunaan aplikasi media sosial dan games pada gadget.

Dalam kondisi ini, anak-anak Gen A dapat dikatakan belum memenuhi kondisi ideal untuk dapat memanfaatkan

teknologi secara maksimal. Teknologi berkontribusi pada pendidikan serta membantu cara dunia berkembang (Ziatdinov \& Cilliers, 2021). Pendidikan merupakan suatu sarana pembelajaran akademik yang sangat penting dan perlu diperhatikan terutama untuk generasi penerus bangsa era sekarang ini. Dari masa ke masa, pendidikan telah berkembang dengan adanya perbaikan dari waktu ke waktu seiring dengan perkembangan zaman (Misla \& Mawari, 2020). Kegiatan belajar mengajar mengandung sejumlah komponen yang meliputi tujuan, bahan pelajaran, kegiatan belajar mengajar, metode, alat, dan sumber serta penilaian (Mustikasari, Supandi \& Damayani, 2019). Peran teknologi harus lebih dimaksimalkan untuk keperluan pendidikan maupun pengembangan skill pada anak. Jika kondisi ideal tidak dapat tercapai maka potensi dan kualitas SDM kedepannya dapat menurun. Anak-anak tersebut juga nantinya tidak memiliki bekal keahlian dalam penggunaan teknologi dan tidak dapat bersaing di dunia global.

Kondisi memiliki pengertian persyaratan atau keadaan (KBBI,Online). Sedangkan, ideal berarti sangat sesuai dengan yang dicita-citakan atau diangan-angankan atau dikehendaki (KBBI, Online). Jadi, kondisi ideal merupakan keadaan yang sangat sesuai dengan hal yang dicitacitakan atau diangan-angankan. Dalam hal ini, kondisi ideal yang ingin dicapai adalah agar anak-anak mampu menggunakan teknologi fundamental komputer sehingga memiliki bekal dan keahlian di masa depan. Life skill penting untuk dikuasai peserta didik sebagai bekal kehidupan di masa mendatang sekaligus untuk membentuk karakter yang baik bagi peserta didik. Kondisi ini memang sepenuhnya harus diperjuangkan agar tercipta SDM yang berkualitas dan terlatih (Ahsani \& Mulyani, 2020). Di era Revolusi Industri 4.0, anak- anak diharapkan mampu menggunakan teknologi untuk menunjang berbagai tugas sekolah dan pengembangan diri.

Gen Alpha yang terlahir di era teknologi yang pesat menjadi kombinasi menarik antara peluang petualangan dan eksplorasi masa depan (Jha, 2020). Untuk itulah, kondisi ideal memang benar-benar 
harus diciptakan agar anak-anak sebagai generasi penerus bangsa memiliki kemampuan yang handal, khususnya dalam bidang teknologi. Selain itu, anak-anak harus sejak dini bisa mengakses media literasi digital untuk menambah wawasan serta mampu menginmplementasikannya ke semua mata pelajaran (Bestari \& Hakiki, 2018).

Penciptaan kondisi ideal merupakan salah satu tantangan yang harus dihadapi. Penciptaan kondisi ideal memang dirasa lebih mudah untuk direalisasikan terhadap anakanak perkotaan karena akses dan fasilitas yang mudah. Sebaliknya, kondisi ideal akan lebih sulit untuk direalisasikan pada anak- anak pedesaan. Pengembangan serta penyebaran TIK yang kurang merata di masyarakat menyebabkan adanya kesenjangan digital terutama di kalangan mayarakat pedesaan atau rural (Oktavianoor, 2020). Hal ini akan menimbulkan ketimpangan antara anak-anak perkotaan dan pedesaan. Ketimpangan ini akan membawa dampak yang sangat buruk karena anak- anak pedesaan bisa menjadi kurang unggul daripada anak- anak perkotaan. Mereka akan lebih sulit bersaing dan kurang berkompeten.

Adapun solusi dari hal tersebut adalah melakukan pelatihan kepada anak-anak di desa agar memiliki pengalaman dan keahlian terhadap bidang teknologi. Solusi dari ketimpangan ini adalah diadakannya kegiatan pengabdian pada masyarakat (P2M). Dengan deskripsi di atas, kegiatan P2M dapat menjadi solusi yang tepat untuk mengurangi kesenjangan pemahaman teknologi yang dialami oleh anak- anak pedesaan.

Beberapa kegiatan pengabdian pada masyarakat mengenai pelatihan teknologi kepada siswa SD telah membuktikan bahwa pelatihan teknologi untuk anak dapat menjadi salah satu strategi untuk mencapai kondisi ideal yang diidamkan. Salah satunya adalah pelatihan Ms.Word di SDN.1 Gulingan, Kabupaten Badung, Provinsi Bali. Pengabdian tersebut dilakukan dengan metode ceramah, praktek secara langsung, dan tanya jawab. Indikator capaian pada pengabdian tersebut adalah 100\% siswa dapat menggunakan Ms.Word untuk membantu proses pengerjaan tugas sekolah. Kesimpulan hasil evaluasi memberikan hasil bahwa efektivitas mencapai 75\%-97,5\%. Efektivitas tersebut didasarkan pada kemampuan siswa-siswa dalam menyelesaikan soal dalam bentuk teks, pembuatan tabel, font, serta penyimpanan data (Santiari \& Rahayuda, 2018).

Pengabdian masyarakat lainnya adalah pelatihan keterampilan dasar komputer dan teknologi informasi di SDN 3 Munduk, Kabupaten Buleleng, Provinsi Bali. Pelatihan yang dilakukan berupa pelatihan Ms.Office dan Ms.Excel. Sosialisasi, pengenalan terhadap menu, latihan menggunakan tools dan operasi dasar pada Ms.Office dam Ms.Word, serta monitoring dan evaluasi memberikan nilai efektivitas sebesar 80\%-90\%.Keberhasilan P2M tersebut juga terlihat dari ketertarikan dan keaktifan peserta dalam bertanya dan menjawab pertanyaan. Peningkatan keterampilan juga terlihat dari hasil tes terakhir yang dilakukan 
(Sudiatmika, Fredlina, \& Astawa, 2020).

Salah satu pengabdian masyarakat lainnya adalah pelatihan keterampilan dasar komputer dan teknologi informasi di SDN 2 Tibubeneng, Kabupaten Badung, Provinsi Bali. Pengabdian pada masyarakat tersebut dilakukan dengan metode demonstrasi, ceramah, tanya jawab, serta praktik langsung penggunaan komputer. Hasil pengabdian menunjukkan pelatihan dapat memberikan pemahaman, pengetahuan, serta keterampilan bagi siswa dalam menggunakan aplikasi Paint, Ms.Word, dan penggunaan internet sehat untuk mencari informasi. Siswa sangat antusisa dalam mengikuti pelatihan serta respon positif ditunjukkan dari indicator kehadiran siswa mencapai $100 \%$.

Kegiatan ini juga memberikan peluang besar bagi anak-anak untuk mengenal teknologi lebih dalam. Keterampilan dalam menggunakan aplikasi pengolah kata maupun gambar harus dipahami oleh anak-anak di Generasi A. Mengingat pada saat ini, segala aspek kehidupan khususnya pendidikan tidak bisa lepas dari campur tangan teknologi (Huda, 2020). Oleh karena itu, penekanan kembali bahwa siapapun di jaman milenial ini dapat memahami dan menggunakan teknologi menjadi dasar pengusulan program pengabdian kepada masyarakat ini.

Pengabdian ini diusulkan dalam bentuk pelatihan bagi anak-anak SD 1 Umeanyar Kecamatan Seririt, Kabupaten Buleleng, Bali. Anak- anak yang diajarkan mulai dari kelas 4, 5 dan 6. Dalam P2M, mereka akan diajarkan untuk menggunakan fasilitas fundamental komputer, yaitu Paint, Microsoft Office Word dan Microsoft Office Power Point.

Pengajaran aplikasi-aplikasi basic ini dibarengi dengan pembelajaran mengetik cepat menggunakan aplikasi Rapid Typing dan mengoprasikan komputer dengan baik dan benar. Dengan demikian, anak-anak yang berada di SD 1 Umeanyar Kecamatan Seririt, Kabupaten Buleleng diharapkan dapat mempersiapkan diri agar mampu melanjutkan ke jenjang lebih tinggi dan memiliki ketertarikan tinggi terhadap bidang teknologi. Pengabdi diharapkan dapat memberikan kesan yang baik untuk anak-anak, agar minat belajar mereka bertambah seiring dengan kebiasaan kegiatan yang diikuti(Negara et al., 2019).Kegiatan ini juga diharapkan mampu melahirkan tunas- tunas muda yang melek teknologi. Oleh sebab itu, pelatihan mengenai fundamental program pengolah kata dan gambar akan sangat penting sebagai bekal untuk melanjutkan ke jenjang pendidikan yang lebih tinggi.

\section{METODE}

Kegiatan pengabdian dilaksanakan di balai banjar Desa Umeanyar Seririt. Metode yang digunakan terdiri dari (1) studi pendahuluan yang dimana memberikan pengenalan kepada siswa tentang dasar-dasar cara mengoperasikan komputer dan aplikasi Microsoft Office. (2) Pelaksanaan pelatihan dan pendampingan, untuk mendapatkan hasil yang optimal siswa dibagi menjadi beberapa kelompok kemudian didampingi oleh pengabdi. 
Jurnal Widya Laksana, Vol.11, No.1, Januari 2022

Tujuannya untuk memudahkan pengabdi melatih dan bertanggung jawab membimbing siswa(Akhmadi et al., 2017). Kemudian yang terakhir (3) tahap evaluasi di tahap ini siswa diberikan sebuah tes membuat satu paragraf, mengubah font, style dan menambahkan sebuah gambar di Microsoft Word. Setelah itu membuat 3 slide presentasi di power point sesuai kreasi masing-masing siswa (Gambar 1).

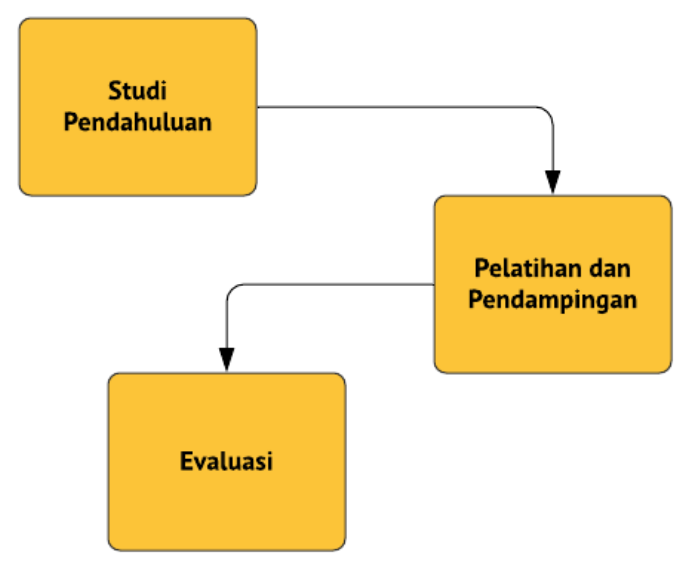

Gambar 1. Bagan Alur Pelaksanaan Kegiatan

Karena kegiatan ini berkelompok siswa dilatih untuk bekerja sama satu sama lain tujuannya melatih kekompakan dan memudahkan siswa untuk menyelesaikan tes yang dikerjakan. Selain itu siswa saling berinteraksi dan bertukar pikiran agar suasana belajar semakin menarik (Mulyadi, 1999). Untuk menambah semangat belajar siswa pengabdi mempersiapkan hadiah di akhir kegiatan, untuk mendapatkan hadiah tersebut siswa harus menjawab pertanyaan atau berhasil mempraktikkan apa yang diarahkan oleh pengabdi. Jika berhasil maka siswa akan memperoleh poin.

\section{HASIL DAN PEMBAHASAN}

Pada saat ini, P2M yang sudah berjalan berfokus pada anak SD. Mengingat perkembangan teknologi sudah berkembang pesat, tetapi penggunaan tekologi pada anak-anak SD tidak berjalan dengan begitu baik, khususnya di wilayah pedesaan. Sebagai pendidikan yang paling mendasar, pendidikan di jenjang SD merupakan hal yang paling penting (Sutarmi \& Suarjana, 2017). Pengajaran terhadap teknologi melalui P2M merupakan salah satu solusi yang baik.

Kegiatan ini dilaksanakan oleh mahasiswa IImu Komputer, Fakultas Teknik dan Kejuruan, Universitas Pendidikan Ganesha. Pengajaran yang diberikan meliputi Paint, Microsoft Office Word, dan Microsoft Office Power Point. Pengajaran berbagai aplikasi basic ini dibarengi dengan pembelajaran mengetik cepat dan mengoperasikan komputer dengan baik dan benar. Kegiatan P2M ini mendapat begitu banyak apresiasi dari anak- anak SD 1 Umeanyar, yang minggu keminggu pesertanya semakin bertambah. Setelah diberikan pengarahan dan pengajaran setiap minggunya, peserta sudah dapat mengoperasikan komputer dengan cukup baik. Setelah beberapa minggu mendapatkan pembelajaran, di setiap akhir materi akan diberikan sebuah tes kompetensi untuk mengetahui sudah sampai mana kemampuan peserta dalam memahami pembelajaran yang sudah diberikan. Metode tes digunakan untuk mengukur ranah kognitif. Test diberikan pada setiap akhir 
pertemuan pada masing-masing siklus (Muliyantini \& Parmiti, 2017).

Kegiatan ini tidak selalu memberikan pembelajaran. Namun, di sela-sela kegiatan akan diadakan games untuk menghindari kejenuhan peserta dan menambah semangat. Hal ini dilakukan mengingat peserta yang diajarkan masih terbilang anak- anak yang gampang merasa jenuh. Kegiatan ini tidak hanya menambah pengalaman belajar, tetapi bagaimana proses mental siswa bisa bekerja sama untuk menyelesaikan sebuah masalah. Dengan ini semua siswa bisa merasakan pentingnya bersosialisasi antar sesama (Dwijayani, 2019)..

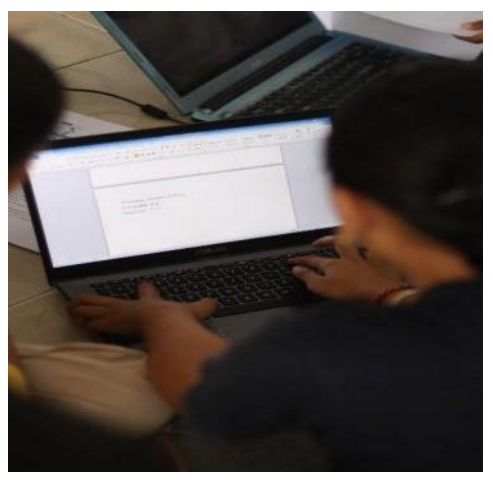

Gambar 2. Pemberian Materi Microsoft Word

Keterbatasan dalam pengabdian masyarakat kadang terkendala dengan waktu yang belum maksimal ini diakibatkan beberapa waktu mahasiswa yang kadang terbentur atara jadwal mengajar dan kegiatan kampus mahasiswa ilmu komputer sendiri.

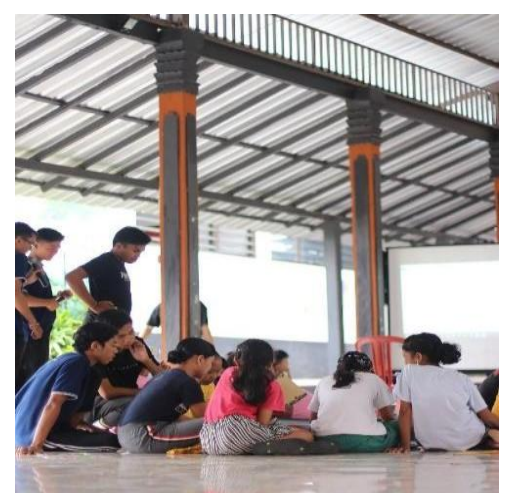

Gambar 3. Pemberian Materi Microsoft Word

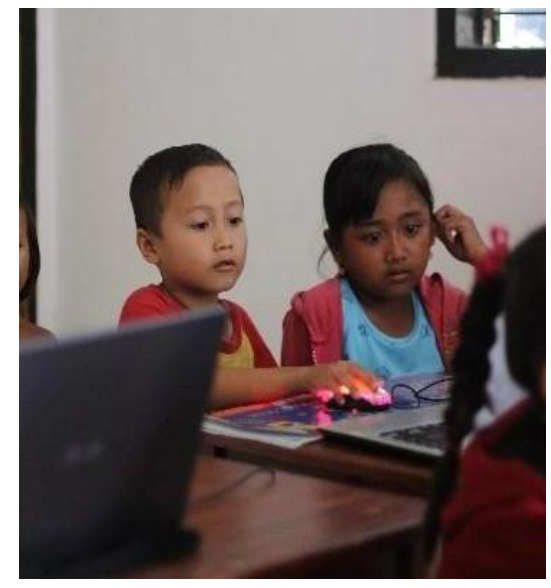

Gambar 4. Pemberian Tes Praktek Kepada Siswa

Peserta anak-anak Sekolah Dasar Negeri 1 Umeanyar sudah berhasil dalam mengoperasikan Aplikasi Microsoft dengan baik. Berdasarkan nilai keaktifan dari 64 siswa, 10 siswa keaktifannya sangat baik dalam menjawab pertanyaan dan 41 siswa aktif berdasarkan absensi. 
Tabel 2. Hasil Evaluasi Peserta P2M

\begin{tabular}{|c|c|c|c|c|c|c|c|c|c|c|c|c|}
\hline \multirow[t]{2}{*}{ No } & \multirow[t]{2}{*}{ Indikator } & \multirow[t]{2}{*}{ Jumlah } & \multicolumn{2}{|c|}{ SB } & \multicolumn{2}{|r|}{ B } & \multicolumn{2}{|r|}{ C } & \multicolumn{2}{|c|}{$\mathrm{K}$} & \multicolumn{2}{|c|}{ SK } \\
\hline & & & $T$ & $\%$ & $\mathrm{~T}$ & $\%$ & $T$ & $\%$ & $\mathrm{~T}$ & $\%$ & $T$ & $\%$ \\
\hline 1 & $\begin{array}{l}\text { Mampu } \\
\text { mengoperasi } \\
\text { kan komputer } \\
\text { dengan baik }\end{array}$ & 64 Siswa & 15 & $\begin{array}{c}23.44 \\
\%\end{array}$ & 44 & $68.75 \%$ & 5 & $7.81 \%$ & - & - & - & - \\
\hline 2 & $\begin{array}{l}\text { Dapat } \\
\text { menggunaka } \\
\text { n aplikasi } \\
\text { Microsoft }\end{array}$ & 64 Siswa & 5 & $7.81 \%$ & 54 & $84.38 \%$ & 5 & $7.81 \%$ & - & - & - & - \\
\hline 3 & $\begin{array}{l}\text { Bisa } \\
\text { menyampaik } \\
\text { an hasil } \\
\text { pekerjaan ke } \\
\text { siswa lainnya }\end{array}$ & 64 Siswa & 10 & $\begin{array}{c}15.63 \\
\%\end{array}$ & 5 & $7.81 \%$ & 49 & $76.56 \%$ & - & - & - & - \\
\hline 4 & $\begin{array}{l}\text { Aktif } \\
\text { berpatisipasi }\end{array}$ & 64 Siswa & 64 & $100 \%$ & - & - & - & - & - & - & - & - \\
\hline
\end{tabular}

Sangat Baik (SB)

Baik (B)

Cukup (C)

Kurang (K)

Sangat Kurang (SK)

$$
\begin{aligned}
& =15 \text { Siswa } \\
& =41 \text { Siswa } \\
& =8 \text { Siswa } \\
& =- \\
& =-
\end{aligned}
$$

\section{KESIMPULAN}

Kegiatan pengabdian pada masyarakat berjalan dengan baik. Simulasi pembelajaran mencerminkan pembelajaran yang mengintegrasikan model pembelajaran inovatif di dalamnya (Nasrun, Faisal \& Feriyansyah, 2018) hal ini terlihat dari antusiasme yang ditunjukkan oleh siswa Sekolah Dasar Negeri 1 Umeanyar dalam mengikuti kegiatan. Selama lima bulan berlangsung, siswa memberikan kesan baik dan aktif, serta siswa bisa mengoperasikan fitur-fitur utama aplikasi fundamental komputer, seperti Paint, Microsoft Office Word, dan Microsoft Office Power Point. Untuk menghindari keterbatasan dan terbeturnya jadwal dengan mahasiswa IImu Komputer, bentuk kegiatan P2M kedepannya akan dirancang lebih feksibel sehingga jadwal dapat diatur sesuai kesepakatan antara siswa dan Mahasiswa IImu Komputer.

\section{DAFTAR PUSTAKA}

Ahsani, E., \& Mulyani, S. (2020). Penerapan E-Learning Berbasis Distance Learning untuk Mengembangkan Life Skill. DIDAKTIKA: Jurnal Pendidikan Sekolah Dasar, 3(2), 115-120. 
Jurnal Widya Laksana, Vol.11, No.1, Januari 2022

doi:

10.21831/didaktika.v3i2.34805

Akhmadi, A., Qurohman, M. T., \& Syarifudin, S. (2017) Peningkatan Kompetensi Auto CAD Bagi Siswa SMK Ma'arif NU Talang Kabupaten Tegal. Jurnal Pengabdian Masyarakat Progresif Humanis Brainstorming, 1(1), 15-21. https://doi.org/10.30591/japhb.v1i 1.683

Bestari, M. P., \& Hakiki, M. H. (2018). Peningkatan Literasi Sekolah Guru dan Siswa melalui Pengabdian Kepada Masyarakat Perpustakaan STIE Perbanas Surabaya. Pustabiblia: Journal of Library and Information Science, 2(1), 137. https://doi.org/10.18326/pustabibl ia.v2i1.137-148

Dwijayani, N. M. (2019). Development of circle learning media to improve student learning outcomes. Journal of Physics: Conference Series, 1321(2), 171-187.

https://doi.org/10.1088/17426596/1321/2/022099

Fadlurrohim, I., Husein, A., Yulia, L., Wibowo, H., \& Raharjo, S. T. (2020). Memahami Perkembangan Anak Generasi Alfa di era Industri 4.0. Focus : Jurnal Pekerjaan Sosial, 2(2), 178.

doi:10.24198/focus.v2i2.26235

Huda, I. A. (2020). Perkembangan Teknologi Informasi Dan komunikasi (TIK) Terhadap Kualitas Pembelajaran di $\begin{array}{llr}\text { Sekolah } & \text { Dasar. } & \text { Jurnal } \\ \text { Pendidikan } & \text { Dan } & \text { Konseling } \\ \text { (JPDK), } & \text { 2(1), } & 121-125 . \\ \text { doi:10.31004/jpdk.v1i2.622 }\end{array}$

Jha, A. K. (2020). Understanding generation alpha. doi:10.31219/osf.io/d2e8g

Misla, M., \& Mawardi, M. (2020). Efektifitas PBL dan Problem Solving Siswa SD Ditinjau dari Kemampuan Berpikir Kritis. Jurnal Ilmiah Sekolah Dasar, 4(1), $60 . \quad$ doi: 10.23887/jisd.v4i1.24279

Muliyantini, P., \& Parmiti, D. (2017). Penerapan Model Pembelajaran Group Investigation (Gi) Untuk Meningkatkan Hasil Belajar IPA Kelas V. Jurnal IImiah Sekolah Dasar, 1(2), 91. doi: 10.23887/jisd.v1i2.10143

Mustikasari, I., Supandi, S., \& Damayani, A. (2019). Pengaruh Model Student Facilitator And Explaining (SFAE) Terhadap Kemampuan Berpikir Kritis. Jurnal IImiah Sekolah Dasar, 3(3), $307 . \quad$ doi: 10.23887/jisd.v3i3.19455

Mulyadi, E. (1999). Penerapan Model Project Based Learning. Jurnal Pendidikan Teknologi Dan Kejuruan, 22(4), 385-395. https://journal.uny.ac.id/index.ph p/jptk/article/view/7836/6708

Nasrun, N., Faisal, F., \& Feriyansyah, F. (2018). PENDAMPINGAN MODEL PEMBELAJARAN INOVATIF DI SEKOLAH DASAR KECAMATAN MEDAN SELAYANG KOTA MEDAN. 
Jurnal Widya Laksana, Vol.11, No.1, Januari 2022

JURNAL

PENGABDIAN

KEPADA MASYARAKAT, 24(2),

671.

Doi:

10.24114/jpkm.v24i2.10359

Negara, H. R. P., Syaharuddin, S., Kurniawati, K. R. A., Mandailina, V., \& Santosa, F. H. (2019). Meningkatkan Minat Belajar Siswa Melalui Pemanfaatan Media Belajar Berbasis Android Menggunakan Mit App Inventor. SELAPARANG Jurnal Pengabdian Masyarakat Berkemajuan, 2(2), 42. https://doi.org/10.31764/jpmb.v2i 2.887

Oktavianoor, R. (2020). Kesenjangan Digital Akibat Kondisi Demografis di Kalangan masyarakat rural. Palimpsest: Jurnal Ilmu Informasi Dan Perpustakaan, 11(1), 9. doi:10.20473/pjil.v11i1.21888

Santiari, N. P., \& Rahayuda, I. G. (2018). Pelatihan MS. word Pada Sdn 1 GULINGAN. Jurnal Pengabdian Masyarakat Borneo, 2(1), doi:10.35334/jpmb.v2i1.407

Sutarmi, K., \& Suarjana, I. (2017). Peningkatan Hasil Belajar Siswa
Menggunakan Metode Problem Solving dalam Pembelajaran. Jurnal Ilmiah Sekolah Dasar, 1(2), $75 . \quad$ doi: 10.23887/jisd.v1i2.10141

Sudiatmika, I. B., Fredlina, K. Q., \& Astawa, N. L. (2020). Pelatihan Keterampilan Dasar Komputer Dan Teknologi Informasi di Sekolah Dasar negeri 3 munduk. Jurnal Karya Abdi Masyarakat, 4(2), 270-275. doi:10.22437/jkam.v4i2.10535

Utami, N. W., \& Putu Ning Septyarini Putri Astawa, N. L. (2020). Pelatihan Keterampilan Dasar Komputer Dan Teknologi informasi bagi siswa sekolah dasar di SD negeri 2 Tibubeneng. Jurnal Pelayanan Dan Pengabdian Masyarakat (Pamas), 4(1), 38-45. doi:10.52643/jppm.v4i1.781

Ziatdinov, R., \& Cilliers, E. J. (2021). Generation alpha: Understanding the next cohort of university students. European Journal of Contemporary Education, 10(3). doi:10.13187/ejced.2021.3.783 